\title{
Um novo mestrado em terapia ocupacional: perspectivas e desafios
}

No ano em que comemoramos cinco décadas da regulamentação da profissão de terapia ocupacional no Brasil identificamos que várias foram as conquistas, mas muitos desafios ainda se apresentam para os profissionais e docentes da área, especialmente em um contexto de crescente valorizaçáo da pesquisa. A produção do conhecimento, no cenário nacional, está intimamente relacionada à pós-graduação, que tem proporcionado o aumento da produção científica e consolidação do conhecimento; o aumento da parceria de pesquisa entre academia e serviço e a formaçáo de recursos humanos (RODACKI, 2015), impactando diretamente na avaliação e reformulação das políticas públicas, com vistas à melhoria dos serviços de saúde prestados e sua gestão. Nesta direção, a criação de espaços para produção do conhecimento e disseminação dos saberes da terapia ocupacional é fundamental, indispensável (MONZELI et al., 2018) e, por que não dizer, vital para a sobrevivência da profissão dentro de ambiente cada vez mais competitivo.

A terapia ocupacional apresenta percurso recente no contexto nacional da pós-graduação, com a criaçáo, em 2010, do primeiro curso de mestrado na Universidade Federal de Sáo Carlos (UFSCar). A ampliação da oferta de cursos de pós-graduação stricto sensu no sistema nacional, nos quais o principal objeto de estudo é a terapia ocupacional, favorece o crescimento, fortalecimento, consolidação e reconhecimento da terapia ocupacional enquanto ciência e deve ser uma meta para os grupos de docentes que vem avançando em pesquisa. A aprovaçáo recente, pela CAPES, de dois cursos de mestrado em terapia ocupacional, um mestrado profissional na Universidade de São Paulo (USP) e outro acadêmico na Universidade Federal de Minas Gerais (UFMG), vem agregar esforços nessa direção.

O Mestrado em Estudos da Ocupaçáo (CPGEO-UFMG), com início das atividades no segundo semestre de 2019, apresenta proposta pautada na articulação de diferentes áreas do conhecimento que contribuem para o avanço do saber interdisciplinar sobre a ocupaçáo e tem caráter inovador ao propor, desde o início do programa, um modo de produção científica mais colaborativo. O curso tem como objetivo formar recursos humanos qualificados para lidar com questôes ocupacionais de forma sistêmica, considerando seus aspectos biológicos, sociais, econômicos, históricos, antropológicos, filosóficos e culturais. Visa também fomentar análise crítica das teorias e recursos que utilizamos, criando ambiente estimulante para a discussão, inovação e geração de ideias que consolidem o estudo da ocupação como área de investimento acadêmico e, ao mesmo tempo, deem suporte à prática baseada em evidências.

O curso conta com uma área de concentração e duas linhas de pesquisa. A área de concentração, denominada "Ocupação, Participação e Inclusão", aborda temas/conteúdos relacionados ao estudo da Ocupaçáo como objeto principal de investigaçáo, com foco na análise da participação das pessoas em situaçôes de vida no que tange às tendências e perspectivas da inclusão social. A linha de pesquisa "Ocupação, Cuidado e Funcionalidade" tem como propósito investigar a influência de fatores intrínsecos e extrínsecos (relacionados ao ambiente, incluindo produtos e tecnologia) ao indivíduo, no engajamento nos papéis ocupacionais. Além disso, enfatiza a compreensão das estratégias de cuidado (avaliação e intervenção) para prevenção, promoção e recuperação da funcionalidade sob perspectivas transdisciplinares. A linha de pesquisa "Ocupação, Políticas Públicas e Inclusão Social" busca: (1) compreender os papéis ocupacionais a partir das dimensóes socioeconômica e relacional, analisando como os aspectos sociais impactam nas oportunidades ocupacionais e na construção da cidadania de diferentes grupos populacionais, sejam eles vinculados à questão de gênero, raça, estigma, cultura, entre outros; (2) investigar condiçôes de risco e de proteção, sobre bem-estar e a participação, bem como analisar a implementação das Políticas Sociais; (3) compreender as estratégias de inclusão social e como o estado, por meio das políticas públicas, atende as necessidades 
e as demandas que tangenciam as vivências ocupacionais no trabalho, lazer, estudo, cultura, atividades domésticas e cotidianas.

O Mestrado em Estudos da Ocupação contará com a participação de docentes permanentes de outras Instituiçóes Federais de Ensino Superior, estimulando a parceria entre pesquisadores e fortalecendo grupos de pesquisa interinstitucionais, bem como ampliando a possibilidade de captação de alunos de outras regiōes do estado, com maior capilarização do curso.

A criação do Mestrado em Estudos da Ocupação é resultado de muita luta, não só dos docentes envolvidos, mas também de colegas que nos estimularam e, de alguma forma, contribuíram para a aprovação da proposta. Representa mais um passo, diante de uma longa trajetória, no sentido da consolidação da terapia ocupacional e da produção do conhecimento no país. Celebramos essa vitória, juntamente com colegas da USP, cientes da nossa responsabilidade e dos desafios que se apresentam diante do contexto atual do país. Esperamos que, em breve, possamos avançar dentro do sistema da pós-graduação, com a aprovaçáo de novos cursos de pós-graduação stricto sensu na área de terapia ocupacional, considerando-se as demandas de um país com de dimensóes continentais e enorme diversidade cultural como o Brasil.

\section{Adriana Maria Valladáo Novais Van Petten, Iza de Faria-Fortini, Lívia de Castro Magalháes}

Mestrado em Estudos da Ocupação, Universidade Federal de Minas Gerais - UFMG, Belo Horizonte, MG, Brasil.

\section{Referências}

MONZELI, G. A. et al. Perspectivas e tendências da Federação Mundial de Terapeutas Ocupacionais: um olhar sobre o Congresso Mundial 2018 - Cidade do Cabo, África do Sul. Cadernos Brasileiros de Terapia Ocupacional, São Carlos, v. 26, n. 3, p. 511-512, 2018.

RODACKI, A. L. F. Editorial. Cadernos Brasileiros de Terapia Ocupacional, São Carlos, v. 23, n. 2, p. 235-236, 2015. 